\title{
DESCRIPTION OF SOME NEMATODE PARASITES INFECTING AMERICAN COCKROACH, PERIPLANETA AMERICANA IN SHARKIA GOVERNORATE, EGYPT

\author{
By
}

\author{
HESHAM M. SHARAF*, ABD-ALLAH A. AL HOOT, FARAG A. AHMED \\ and AYA A. MOHAMAD
}

Department of Zoology, Faculty of Science, Zagazig University, Zagazig,

Egypt ( ${ }^{*}$ Correspondence: sharaf_hesham@yahoo.com)

\begin{abstract}
In present study, three known species insect parasitic nematodes were recovered from Periplaneta americana collected from uptown Zagazig City. These nematodes were 1- Hammerschmidtiella dieingi, 2- Leidynema meerutensis, and 3-Thelastoma bulhoesi collected from the hindgut of the host $P$. americana. These parasites were studied by using light microscope, SEM and TEM.
\end{abstract}

Key words: Periplantea americana, Hammersmiditiella sp., Leidynema sp., Thelastoma sp., SEM, TEM.

\section{Introduction}

The American cockroach (Periplaneta americana), also colloquially known as the water-bug, but not a true water-bug since it is not aquatic (Hall, 2002), or misidentified as the palmetto bug is the largest species of common cockroach (Poertner, 2013). Despite the name, $P$. americana was introduced to what is now know the United States from Africa as early as 1625 (Bell and Adiyodi, 1981). American cockroaches are also known as plagues in the warm The Me diterranean Coast of Spain as well as in southern Spain and southern Portugal (starting from Barcelona to the Algarve) and in the Canary Islands, where the winters are mild/ warm and frost-free, and the summers are hot (Copeland, 2003). American cockroaches can become a public health problem due to their association with human waste and disease and their ability to move from sewers into homes and commercial establishments in caves, mines, privies, latrines, cesspools, sewers, sewage treatment plants, and dumps (Komatsu et al, 2013). The presence of cockroaches in these habitats is of risky epidemiological significance. At least 22 species of pathogenic human bacteria, viruses, fungi, and protozoans, as well as five helminthic worms' species, were isolated from field collected American cockroaches. Also, they are aesthetically displeasing because they can soil items with their excrement and regurgitation (Baldwin and Koehler, 2007). In Taiwan, from 250 adult cockroaches, 38 species of gramnegative bacteria, 20 species of glucose nonfermenter bacilli and 6 species of grampositive bacteria were isolated (Pai, 2003). Besides, in Nigeria many protozoan and helminthes as cysts of $E$. hystolitica and Balantidium coli, oocysts of C. parvum, $C$. cayetenensis and Isospora belli, ova of Ascaris lumbricoides, Anchylostoma deodunalae, Enterobius vermicu-laris, Trichuris trichura, and larva of Strongyloides stercoralis 234 cockroaches trapped from different human dwellings' sites. In Egypt, cockroaches, apart as others insects, spiders, scor-pion, ticks, mites parasitic worms, bacteria, or other living organisms causes Entomophobia or acarophobia, parasitic dermatophobia or delusional parasitosis (Sabry et al, 2012). Stankus et al. (1990) reported that they have a supplementary role in the spread of diseases, or suspected carriers of the organisms causing: diarrhea, dysentery, cholera, leprosy, typhoid fever, viral diseases such as poliomyelitis as well as eggs of parasitic worms and may cause allergic reactions, including dermatitis,

The study aimed to describe three parasitic nematodes isolated from Periplanata americana collected from indoors and outdoors uptown of Zagazig City, Sharkia Governorate, Egypt.

\section{Materials and Methods}

A total of 160 Periplaneta americana 
(Linnaeus, 1758) were collected and identified. They were anesthetized with chloroform and then dissected in Petri dishes filled with the normal saline solution under a stereoscopic binocular microscope. Nematode parasites were removed from the hindgut of 119 roaches and picked up with the help of a fine glass dropper. Parasites were washed in normal saline and fixed in hot $70 \%$ ethanol. For the study of morphology, parasites were cleared in glycerin and photomicrographed by using Olympus research microscope, and measured with an ocular micrometer.

SEM: the heat killed nematodes were transferred in primary fixed in Karnovasky's fixative for an overnight and then transferred in $2.5 \%$ glutaraldehyde. The fixed nematodes were washed with $0.1 \mathrm{M}$ phosphate buffer ( $\mathrm{pH}-7.2)$ at $4^{\circ} \mathrm{C}$ and gradually dehydrated in different grades of acetone. The dehydrated specimens were dried by critical point drying method using liquid $\mathrm{CO}_{2}$ and then mounted on aluminum stubs and gold coated (Green et al, 1975). Photography was done using LEO435 VP SEM, Mansoura University and measurements were recorded with LEO-32 annotation program.

TEM: Samples for transmission electron microscopy phoretic or parasitic stages of nematodes were fixed in $1 \%$ glutaraldehyde and $0.6 \%$ sucrose in $0.1 \mathrm{M}$ phosphate buffer ( $\mathrm{pH}$ 7.4) for more than $24 \mathrm{~h}$. The head or tail regions were cut off and left in the same fixative for more than $24 \mathrm{hrs}$. After rinsing in the same buffer (six times, 10 min each), the nematodes were post-fixed in $1 \%$ osmium tetroxide for $90 \mathrm{~min}$ in same buffer. Fixed nematodes were dehydrated in a graded ethanol $(50 \%, 70 \%, 80 \%, 90 \%, \& 99.5 \%)$. They were cleaned three times with propylene oxide $10 \mathrm{~min}$ each and infiltrated overnight in a mixture of 50\% Eponateresin and $50 \%$ propylene oxide and an undiluted resin.

\section{Results}

A total $119 / 160 P$. americana were infected with three nematode parasites: 1 Hamm-erschmidtiella dieingi, 2- Leidynema meerutensis, and 3-Thelastoma bulhoesi.
1- Hammersmiditiella dieingi female (figs. 1-3): The cephalic extremity rounded. Cuticle striated with rings along entire body. Mouth surrounded by three toothed lips and eight labial papillae. Amphids small and pore shaped. Buccal capsule is short, wide with two mobile teeth on each side of mesostom. Esophagus short and strong, the posterior part of the corpus forms the metacarpus valvate, the anterior and posterior parts of the corpus are differentiated easily, isthmus cylindrical and thin surrounded by nerve ring, ending in a rounded basal bulb heavily muscled and vulvae. Excretory pore is situated at the base of the esophagus. The vulva is slightly protruding and lies in the anterior third of the body. Vagina long and heavily muscled.

Male (figs.4, 5): Body small, truncated in appearance, slightly curved ventrally at the posterior end upon fixation. Cuticle finely striated up to the posterior region of the corpus from the head end. Narrow lateral alae present. Esophagus $0.116 \mathrm{~mm}$ long, devoid of pseudobulb. Corpus cylindrical, $0.063 \mathrm{~mm}$ long, $0.007 \mathrm{~mm}$ wide, isthmus measures $0.036 \mathrm{~mm}$ in length, $0.007 \mathrm{~mm}$ in width. End bulb ovate, $0.019 \mathrm{~mm}$ long, $0.019 \mathrm{~mm}$ wide, with buccal cavity $2.43 \times 4.8 \mathrm{~mm}$. Nerve ring at $0.085 \mathrm{~mm}$ from anterior end.

2- Leidynema meerutensis female (figs.69): Body cylindrical, $2.5 \mathrm{~mm}$ in length and with a maximum body width of $0.28 \mathrm{~mm}$; head with 2 nd annulus much wider and with close-set of 5annuli and then annuli expand abruptly in both, its length and width. First annual with 8 pairs of labial papillae have a surrounding mouth. The cuticle is closely annulated throughout the body length. Lateral alae prominent, each one terminates into a spine-like projection at the posterior. Esophagus is $0.37 \mathrm{~mm}$ long occupying anterior $14 \%$ of body length with a $0.29 \mathrm{~mm}$ long corpus, $0.020 \mathrm{~mm}$ long distinct isthmus and an end bulb of $0.11 \times 0.10 \mathrm{~mm}$ dimension.

Corpus has two distinct regions, the anterior half is narrow and its posterior part is cylindrical and broader. Intestine prominent- 
ly enlarged at the anterior end and is provided with a posteriorly directed much-enlarged characteristic oblong, blind intestinal diverticulum. Vulva transverse in orientation and slightly anterior to middle of body at 1.27 $\mathrm{mm}$ from anterior end $(\mathrm{V} \%=48 \%)$.

3- Thelastoma bulhoesi female (Figs.10-12): Body relatively robust, widening from base of first cephalic annual, maximum body width at vulva level, directed towards anus. Cuticle annulated from end first cephalic annuli to anus level. Annuli more evident at cervical region level; Annuli of cervical region of cardia (ca) $5 \mu \mathrm{m}$ in width, then increases to ca. $10 \mu \mathrm{m}$ at posterior body half; without lateral alae.

Head with eight paired labiopapillae arranged two sub-dorsal pairs and two subventral pairs. Labiopapillae is C-shaped, elevated, with a deep center. Amphids lateral, as crescent-like pores, located at cuticular elevations top. Buccal aperture triradiate, with three hexagonal labia, arranged as two sub-dorsal and one ventral. Distal side each labia with a rounded cleavage that combines as a circular aperture when 3 labia in contact. First cephalic annule cone-like, truncate, barely inflated, ca. 1.5 head long. Esophagus consists of a muscular, cylindrical procorpus with diameter similar to all its extension. Isthmus is short, slightly slender than procorpus. Basal bulb rounded, valveplate well developed. Tail subulate, filiform, ending in a fine tip.

SEM of female $T$. bulhoesi (Figs. 13, 14) showed excretory pore, intestine, anus, vulva, anterior annulae and eggs, TEM showed that the cuticle surface has longitudinal incisures. Cuticle layering of body consists of acortical, medial, and basal layer. The external cortex can be resolved into at least five layers (i) a moderately dense outer layer, (ii) a thin electron-lucent layer, (iii) a thin electron dense layer, (iv) a thick moderately dense layer, and (v) a dense inner layer. The internal cortex is relatively homogeneous, although externally it may be of slightly greater density. In addition to nuclei, the hy- podermis generally includes large numbers of organelles and other structures. The chords are filled with mitochodrian (M), sarcoplasmic body (SB) and thin, dense bands (TD) as (Figs.15-18)

\section{Discussion}

In the present study, nematodes were relatively high $(74 \%)$ in comparison with other nematodes: $5.9 \%$ for Thelastomaalli, $15.3 \%$ for Leidynema appendiculata and $20.4 \%$ for Hammerschmidtiella indicus infecting Periplaneta americana (Kumar and Singh, 2014). The present study observed a high rate of infection with intestinal parasites in cockroaches $(74 \%)$. These are similar to the previous studies the prevalence rate of intestinal parasites of cockroaches was less than recorded by Fotedar et al. (1991) when they discovered $99.4 \%$ of cockroaches collected from hospital and 94.2\% cockroaches collected from residential areas were transporting medically important microorganisms and higher than that of Thyssen et al. (2004) who reported $58.3 \%$ of Periplaneta americana carried helminthes.

By several ways helminthes can be carrying to human, but by insects little attention has been given to vector or mechanical transmission of infective forms (Chan et al, 2004). This study reported the importance parasites and role of insects as mechanical vectors of helminthes parasites, the most important role is the arthropods play is in carrying germs and parasites. Cockroaches are arthropod transmitters of disease, playing both as mechanical vectors and as reservoirs of pathogenic agents.

As to Leidynema appendiculata Ozawa et al. (2014) in Japan reported that the smokybrown cockroach Periplaneta fuliginosa has spread all over the world, and is now one of the most undesired invasive alien pests. Because cockroaches are generally infected by the lastomatid nematodes, they are being distributed around the world with their zoonotic parasitic nematodes. They added that $100 \%$ Japanese individuals in contact with Periplaneta were infected with this species 
H. diesingi (Hammerschmidt, 1838) can be distinguished by the nerve ring located anterior to metacorpus, the excretory pore at the base of the esophagus, and in the male by one pair preanal papillae near the anus and a single unpaired ventral papilla near the base of a tail appendage. Sriwati et al. (2016) in Japan isolated H. diesingi (Hammerschmidt, 1838) was from $P$, americana was recorded in Japan. They added that DIC and SEM confirmed that their specimens agreed with previous records of $\mathrm{H}$. diesingi from other countries. Jex et al. (2005) reported that $H$. hochi was different mainly by having pear-shaped eggs, the nerve ring is posterior to metacorpus, lateral alae are absent, and tail conoid and subulate. H. manohari (Rao, 1958) is characterized by cuticle, striated throughout body length, nerve ring enclosed the metacarpus, and in the male by one pair of preanal, two pairs of adanal and an unpaired median postanal papillae; of two pairs of adanal papillae, one located close to anus and other one well improved, projects laterally from the tail appendage.

\section{Conclusion}

No doubt, cockroaches could be mechanical vector of medical pathogens, and inhabitants of urban centres are at the greatest risk of infection. There must be further analysis of the cockroach and parasite relations.

\section{References}

Baldwin, RW, Koehler, PG, 2007: Toxicity of commercially available household cleaners on cockroaches, Blattella germanica and Periplaneta americana. Florida Entomol. 90:703-9.

Bell, WJ, Adiyodi, KG, 1981: American Cockroach. Springer. ISBN 978-0-412-16140-7.

Chan, O, Lee, K, Hardman, J, Navin, J, 2004: The cockroach as a host for Trichinella and Enterobius vermicularis: Implications for public health. Hawaii Med. J. 63, 3:74-7.

Copeland, M, 2003: Cockroach. London: Reaktion Books LTD. ISBN 978-1-86189-192-

Fotedar, R, Shriniwas, UB, Verma, A, 1991: Cockroaches (Blattella germanica) as carriers of microorganisms of medical importance in hospitals. Epidemiol. Infect.107, 1:181-7.
Green, CD, Stone, AR, Turner, RH, Clark, SA, 1975: Preparation of nematodes for scanning electron microscopy. J. Microsc. 103, 1:8999.

Hall, JH, 2002: Dictionary of American Regional English (illustrated ed.). Harvard University Press. ISBN 978-0-674-00884-7.

Jex, AR, Schneider, MA, Rose, HA, Cribb, T H, 2005: The Thelastomatoidea (Nematoda: Oxyurida) of two sympatric panesthiinae (Insecta: Blattodea) from South-Eastern Queensland, Australia: Taxonomy species richness and host specificity. Nematology 7, 4:543-75.

Komatsu, N, Kishimoto, T, Uchida, A, Ooi, H K, 2013: Cockroach fauna in the Ogasawara Chain Islands of Japan and analysis of their habita ts. Trop. Biomed. 30, 1:141-51

Kumar, SPR, Singh, HS, 2014: Morphological analysis of Insect parasitic nematodes of Periplaneta americanaof Meerut Region, U.P. India. Inter. J. Sci. Res. Educ. 2:661-83.

Ozawa, S, Vicente, CS, Sato, K, Yoshiga, T, Kanzaki, N, et al, 2014: First report of the nematode Leidynema appendiculata from Periplaneta fuliginosa. Acta Parasitol. 59, 2:219-28.

Pai, HH, 2013: Multidrug resistant bacteria isolated from cockroaches in long-term care facilities and nursing homes. Acta Trop. 125, 1: 18-22.

Poertner, BO, 2013: Palmetto Bug: Roach or Beetle? Quit Debating, We Have The Answer. Orlando Sentinel.

Rao, PN, 1958: Studies on the nematode parasites of insects and other arthropods. Arquivos do Museu Nacional. Rio de Janeiro, 46:33-84.

Sabry, AH, Fouad, MA, Morsy, AT, 2012: Entomophobia, acarophobia, parasitic dermatophobia or delusional parasitosis. J. Egypt. Soc. Parasitol. 42, 2:417-30.

Shukolyukov, SA, 2008: Discovering the Achievements of the American Cockroach. University Science News, USA.

Sriwati, R, Ozawa, S, Morffe, J, Hasegawa, K, 2016: First record of Hammerschmidtiella diesingi (Hammerschmidt, 1838) (Oxyuridomorpha: Thelastomatidae) parasite of Periplaneta americana (Linnaeus, 1758) (Blattodea) in Japan, morphological and molecular characterization. Acta Parasitol. 61, 4:720-8.

Stankus, RP, Horner, E, Lehrer, SB, 1990: Identification and characterization of important cockroach allergens. J. Aller. Clin. Immunol. 86: 
781-7.

Tatfeng, YM, Usuanlele, MU, Orukpe, A, Digban, AK, Okodua, M, et al, 2005: Mechanical transmission of pathogenic organisms: Role of cockroaches. J. Vect. Bor. Dis. 42, 4:129-34.
Thyssen, P, Moretti, T, Ueta, M, Ribeiro, O, 2004: The role of insects (Blattodea, Diptera, and Hymenoptera) as possible mechanical vectors of helminthes in the domiciliary and peridomiciliary environment. Cad. Saude Public. 20, 4:1096-102.

\section{Legend of Figures}

Figs.(1-3) Morphology of female Hammersmiditiella dieingi showing pharynx ( $\mathrm{Ph}$.), pseudobulb ( $\mathrm{Pb}$.), Isthmus(Is.), End bulb (Eb.), gastric pouch (G.p.), Intestine (In.), Eggs (E.), ovaries (O.), Anus (A), Tail (T), Buccal capsule (B.C) with different magnifications X, 60 \& 120 Figs.(4,5) Morphology of male Hammersmiditiella dieingi (Chitwood, 1932). Showing pharynx (Ph.), End bulb (Eb.), gastric pouch (G.p.), Intestine (In.), Eggs (E.),Testis(Te), Vesicula seminalis (V.S). X, 80

Figs. (6-9) Photomicrographic details of Leidynema meerutensis n. sp. (female) (Leidy, 1850). Showing head (H), Oesophagus (O), End bulb (Eb), Intestine (In), Excretory pore (E.P), Intestinal Diverticulum (I.D), vulva (V), Anus(A), Tail (T), Egg(E). X,120

Figs.(10-12) Thelastoma bulhoesi (de Magalhaes, 1900). Female. Showing Excretory pore(Ep), Posterior bulb (Postb) Nerve Ring (N.R), Pharynx(Ph), Isthmus (Is),End bulb(Eb), gasric pouch (G.p), Intestine

( In), Ovaries (O), Uterus (Ut), Anal gland (A.G), Anus (An) with different magnifications X, 60 \& 120

Figs.(13,14). Scanning electron micrographs of Thelastoma bulhoesi (Female). Showing Excretory pore(Ep), Intestine( In), Anus (An), Vulva (V), anterior annulae (Ant.A), Eggs(E).

Figs.(15-17): Cross section through lateral field with two incisures showing layering External cortex (Ec), Internal cortex (Ic), medial layer (Md), Basal layer (B), electron- lecent zone (LZ).

Fig.(18): Cross section through hypodermal chord showing nucleus (Nu), nucleolus (Nc), mitochodrian (M), sarcoplasmic body (SB) and Thin, dense bands (TD).
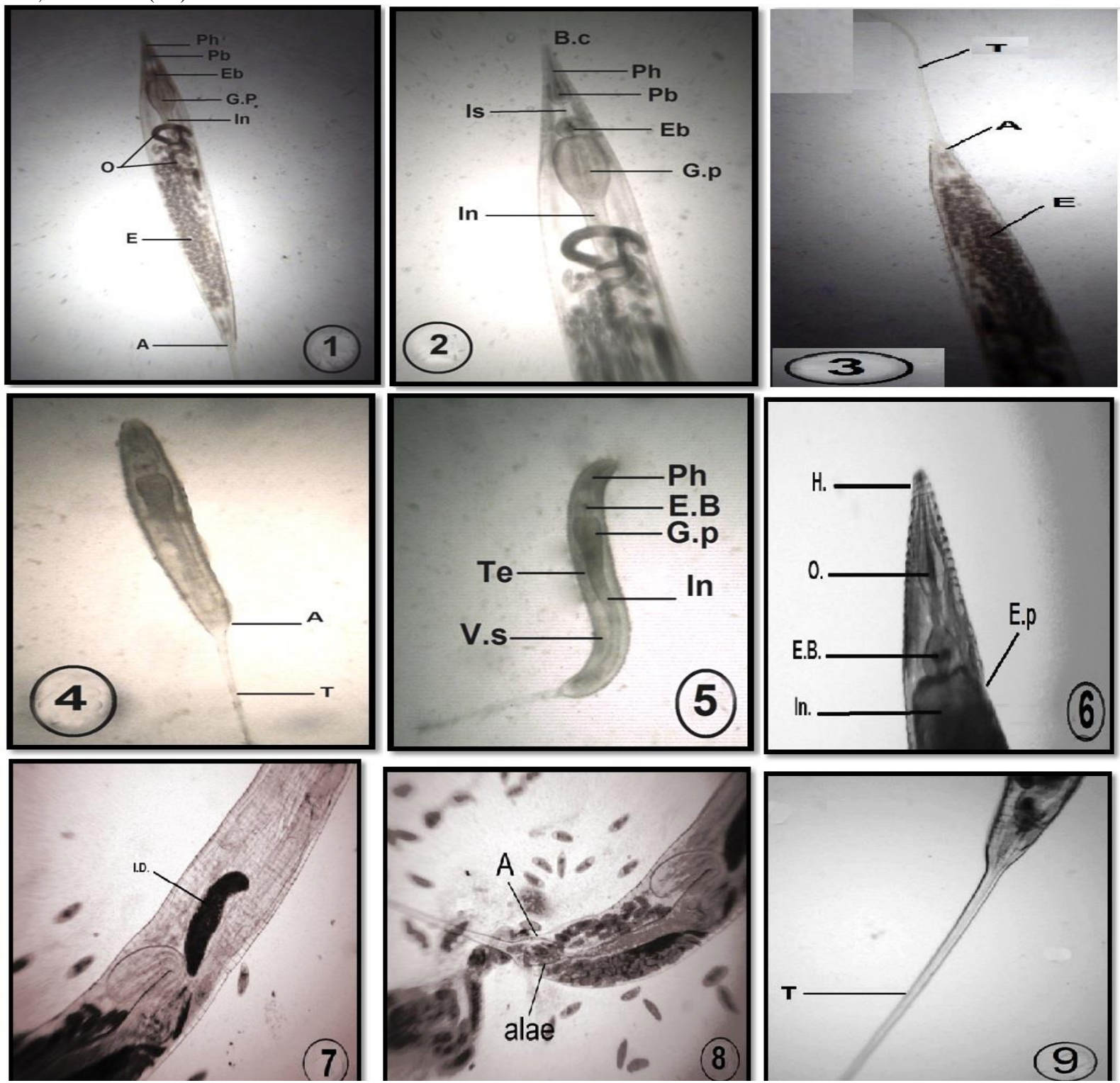

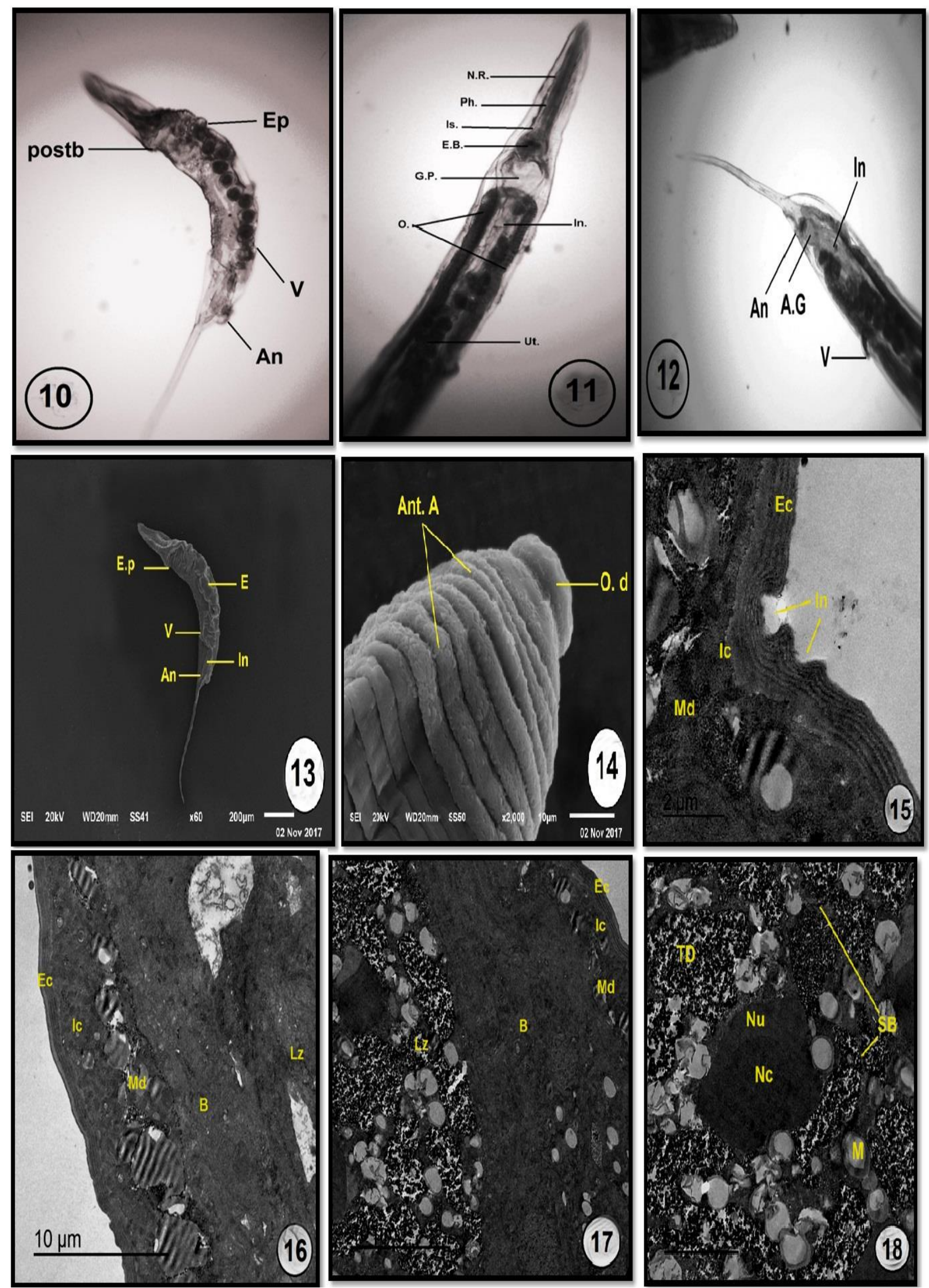